\title{
ANÁLISIS JURÍDICO A LA FIGURA DEL TRABAJO A DISTANCIA
}

\author{
JURIDICAL ANALYSIS OF THE FIGURE OF TELEWORK
}

\begin{abstract}
ISAÍAS RODRÍGUEZ REYES*
Abogado

RESUMEN: Se analiza el escenario legal de los trabajadores a domicilio y teletrabajadores en Chile. En consideración a la inexistencia de una normativa expresa que los regule y el desarrollo que esta modalidad de trabajo ha alcanzado en el mundo empresarial de otros países. Asimismo, se discuten las bases que debiera establecer una futura normativa al respecto, teniendo presente el último proyecto de ley presentado en el año 2011.
\end{abstract}

Palabras clave: trabajo a domicilio - teletrabajo - trabajo a distancia - proyecto de ley que regula el contrato de trabajo a distancia

ABSTRACT: This article analyzes the legal stage of homeworkers and teleworkers in Chile. In view of the absence of express rules that regulate and development compared to this type of work has been achieved in the business of others countries. Also, discusses the bases should establish a future regulation on the matter, bearing in mind the last bill presented in 2011.

Key words: homework - telework - telecommuting - work to distance's bill

\section{INTRODUCCIÓN}

Desde sus orígenes, el reducido grupo de quienes han trabajado a domicilio siempre ha debido lidiar, por regla general, con una mayor desprotección y falta de regulación específica de parte de la norma laboral ${ }^{1}$. Respondiendo mayoritariamente a una antigua suerte de cifra negra del empleo, trabajadores se desempeñaron en condiciones de trabajo con riesgos graves para su salud y seguridad, teniendo como contraparte una exigencia alta de rendimiento ${ }^{2}$. En este sentido la labor fiscalizadora del Estado, en décadas pasadas, fue trascendental en poder desentrañar situaciones de patente ilegalidad donde se expuso a trabajadores a realizar labores industriales o textiles de riesgo en sus propios hogares, bajo deplorables condiciones ${ }^{3}$.

\footnotetext{
* Abogado. Licenciado en Ciencias Jurídicas y Sociales de la Pontificia Universidad Católica de Chile. Las bases de esta monografía se escribieron el año 2012, con oportunidad de evaluación del Diplomado de Derecho del Trabajo y Seguridad Social de la Pontificia Universidad Católica de Chile. Contacto: iorodrig@uc.cl

1 Morales y Romanik (2011) p. 18.

2 Henríquez (2005) p. 19.

3 Montero (2000).
} 
Desaparecida dicha forma encubierta de trabajo industrial, el trabajo a domicilio con el transcurso del tiempo siguió ejecutándose en diversas labores tales como: Estudios de Sociología, Investigaciones académicas o consultorías permanentes encargadas en disciplinas de las Ciencias Sociales, Labores de Diseño Gráfico, Informes contables o de auditoría, Análisis de Seguros, o Cronista de Medios de Comunicación ${ }^{4}$. Trabajos que si bien en muchos casos, pudiesen reunir todos los elementos propios del vínculo de subordinación y dependencia, por años han permanecido en la llamada zona gris, relevándose injustamente del primer orden de aplicación de la norma tutelar.

Posteriormente con el arribo de las nuevas tecnologías, el trabajo a domicilio adoptó una renovada fuerza, pues pese a persistir sus características principales, logró con la aparición del teletrabajo, legitimarse socialmente como modalidad de ejecución de la actividad laboral. En efecto, el nuevo trabajo a domicilio mantuvo el distanciamiento entre empleador y trabajador, pero esta vez añadió la implementación de las Tecnologías de la Informática y la Comunicación (TIC). Así, el nacimiento del teletrabajo produjo un verdadero impacto en el análisis de las ciencias sociales, lo que llevó en la década de los $90^{\prime}$ a muchos a exageradas reacciones que planteaban un verdadero cambio de paradigma de las relaciones laborales.

Sin embargo, las expectativas de un venidero cambio de carácter revolucionario en las relaciones laborales se fueron diluyendo conforme transcurrieron los años ${ }^{6}$. La timidez empresarial en su implementación y la desconfianza de la parte trabajadora respecto de una eventual precarización del vínculo, conspiraron con una multiplicación masiva de los vínculos de este tipo.

Actualmente, fracasado dicho discurso futurista al examinar nuestro Código del Trabajo, podemos observar que la situación legislativa no es muy distinta a la que existía previa a la implementación de las TIC. Pese a no existir estudios recientes, sólo proyectando los datos de las investigaciones efectuadas a comienzos de la década pasada ${ }^{7}$, así como los entregados por la Encuesta Casen del año $2009^{8}$, es factible evidenciar que, aún aludiendo hoy por hoy a un minúsculo sector de trabajadores ${ }^{9}$, muchos de los trabajos caracterizados han continuado ejecutándose parcial o totalmente a domicilio, reproduciendo necesariamente casi idénticos escenarios legales de antaño.

Recubierta hoy de la denominación doctrinal de Trabajo a Distancia ${ }^{10}$, las labores a domicilio con o sin uso de TIC's, dan cuenta hoy en día de una falta de regulación expresa de la norma de orden público nacional, que no puede sino originar, que vínculos de trabajo subordinado reales y efectivos se mantengan condiciones laborales desmejoradas al desenvolverse, en muchos ámbitos de su ejecución, en un contexto de impropia autonomía.

\section{CONCEPTO}

La Organización Internacional del Trabajo (OIT) define trabajo a domicilio como "aquel que se realiza para un empleador o un contratista en virtud de un acuerdo, con arreglo al cual se efectúa el trabajo al exterior de la empresa o taller, en el lugar que elige el trabajador, que es a me-

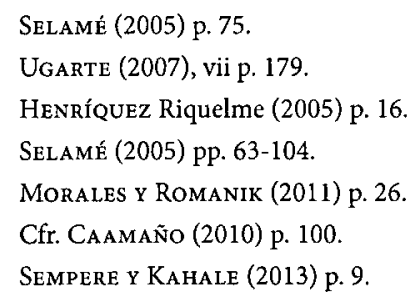


nudo su propio hogar, por lo general, sin la fiscalización directa de quiénes lo encargan" (Organización Internacional del Trabajo, 1994). Lo distingue esencialmente del trabajo común y corriente, el hecho que se realice a distancia, en tanto, empleador y trabajador no comparten físicamente el mismo recinto en el desarrollo de la actividad ${ }^{11}$.

Por su parte, el teletrabajo ha sido caracterizado por la Organización Internacional del Trabajo como la "forma de trabajo efectuada en un lugar alejado de la oficina central o del centro de producción y que implica una nueva tecnología que permite la separación y facilita la comunicación. Configurándose una modalidad de trabajo a domicilio, que requiere la implementación de tecnologías de la información en su ejecución. En este sentido, la particularidad que representa el Teletrabajo, refiere a la necesidad que las actividades deban realizarse con la utilización de medios telemáticos o tecnologías que permitan la comunicación a distancia ${ }^{12}$, siendo el internet la herramienta más trascendente en cuanto engloba, teléfono, correo, videoconferencias y mensajería instantánea ${ }^{13}$.

Delimitados ambos conceptos, emerge en la comparación una indudable relación géneroespecie $^{14}$. Sin embargo, como se señaló, el primer término mantiene los resabios a la reseñada concepción antigua de trabajo industrial doméstico ${ }^{15}$, por cuanto, al aplicarse hoy en día, no parece cobijar al teletrabajo, sino derechamente responder a un concepto distinto. Más distancia han cobrado los conceptos, en razón de la actual implementación masiva de tecnología en la actividad laborativa, que parece haber consolidado la apropiación de la naturaleza del trabajo a domicilio a la referencia necesaria al teletrabajo.

De esta forma, en observancia de ambas figuras, más que distinguirlas y propender a su tratamiento diferenciado, se debe tender a un relato común ${ }^{16}$, entendiendo que el trabajo a domicilio de nuestros tiempos, es el teletrabajo. Buscando precisamente englobar ambos términos, con

1 Guidi (2000) pp. 3-5.
12 Bot'Tos (2008) p. 33.

13 Interesante sería realizar un estudio acerca de las ventajas e inconvenientes que trae aparejado la aplicación de un sistema de teletrabajo. En base a lo expuesto en Teletrabajo, una expresión de flexibilidad laboral por ConTreras (2001). Ventajas: a) Ahorro empresa infraestructura, b) Disminución gasto general de la empresa c) Flexibilidad y Mejora en la calidad de vida. d) Protección del núcleo familiar e) Optimización del tiempo. f) Reducción del tráfico vehicular. Inconvenientes: a) Pérdida de confidencialidad de la información. b) Incremento en costos de equipamiento. c) Pérdida de identidad con empleador. d) Reducción de interacción social. e) Debilitamiento del sindicalismo.

14 Thibaulr (2000) p. 26.

15 Concepto que tiene sus orígenes anteriores incluso al nacimiento del Derecho del Trabajo, siendo una modalidad muy extendida en Inglaterra en tiempos de la Revolución Industrial. Al respecto Carro (1992) indica: "Se comprueba que determinadas operaciones relacionadas con la industria textil, calzado o confección, principalmente, eran susceptibles de ser realizadas en el domicilio de quiénes las efectuasen y no en el taller o la fábrica, lo cual liberaba al empresario de las obligaciones propias de los locales, máquina, horarios, así como le permitía tener una plantilla de trabajadores fijos más reducida. Por antonomasia a este tipo de trabajo se le aplica la expresión sweating systeme (sistema que hace sudar) y que para definirlo nada mejor que transcribir un informe que se hacía en Londres, en 1830 ante la Comisión de Tejedores Manuales: "Existen unos sastres denominados sweaters que emplean mujeres y niños hasta el número de doces veces. Recogen las prendas los sábados y pagan a sus obreros." "

16 Distintos caminos podemos constatar por la experiencia comparada, ciertas legislaciones que han optado por englobar ambos términos dentro de una misma norma, como por ejemplo la legislación española. Así, en el Estatuto de Trabajadores de España, (art. 13) Trabajo a Distancia, se establece sólo como requisito para la aplicación del contrato especial que la actividad se realice de manera preponderante en el domicilio del trabajador o en el lugar libremente escogido por éste. Por otra parte, en Colombia por la Ley 1221 de 2008, ha definido un ámbito de aplicación exclusivo a la figura del teletrabajo propiamente tal, es decir, conceptualizándolo como una forma de organización laboral ligada derechamente al uso de tecnologías de la información y telecomunicaciones (TIC). 
Isaías Rodríguez Reyes / Análisis juridico a la figura del trabajo a distancia

el propósito de consolidar un tratamiento legislativo único, surge en los últimos años la categoría doctrinal del trabajo a distancia ${ }^{17}$.

Bajo esta consideración, en el presente análisis jurídico debemos relevar la excesiva preponderancia que por años se le ha otorgado a la variable tecnológica, en tanto, pese a ser un factor a considerar, ha recubierto de una impropia aura de profesionalidad tecnológica ${ }^{18}$ que ha logrado que olvidemos que a todas luces se trata de una actividad laboral como cualquier otra. Luego, una futura regulación acerca del trabajo a domicilio debiera forjar una conceptualización que no sólo apunte al teletrabajo, evitando que un mayor o menor grado de intervención de las TIC determine el sentido y alcance de la protección de la ley.

\section{DESARROLLO DOCTRINAL}

Desde la masificación de las tecnologías de la información en la ejecución de las actividades laborativas, se comienza a escribir respecto a la figura con mayor frecuencia.La novedad que introdujo la aparición del teletrabajo, fue en la doctrina comparada generando rápidas y desmesuradas expectativas respecto a su crecimiento ${ }^{19}$. Académicos como Dennis J. Kravett llegaron a sostener que en algunos años recordaremos ésta época como la que el hombre tuvo que salir de su hogar para concurrir al trabajo, pronosticando el fin del trayecto del hombre al lugar del trabajo en razón de la inmediatez que trae consigo la tecnología. ${ }^{20}$

Naturalmente dichas reflexiones repercutieron en el iuslaboralismo, que se remeció con tales vaticinios y ante la certeza de un paulatino crecimiento de las tecnologías en el desarrollo de la actividad laborativa. Las publicaciones comenzaron por caracterizar al teletrabajo como una figura polisémica ${ }^{21}$, advirtiendo que su ejecución podría darse bajo distintas modalidades, donde la

17 La referencia más antigua a Trabajo a Distancia, encontrada con objeto de la construcción del presente artículo se halla en: Montero (2000) p. 19. En dicha publicación se tratan los conceptos de trabajo a domicilio y teletrabajo, para referir a ambos por Trabajo a Distancia. Luego, en Sempere y Kahale (2013) p. 9, se refiere a la reciente ley española RDL 3/2012, que define el Trabajo a Distancia. El propósito de la iniciativa legislativa fue regular el teletrabajo, añadiéndolo a la normativa existente de trabajo a domicilio.

En nuestro pais, el Proyecto de Ley N²24-558 propone regular el Contrato de Trabajo a Distancia. Su definición precisamente aúna ambos términos, exigiendo sólo que el trabajo se ejecute fuera de las dependencias de la empresa. Comentarios respecto de la terminología Contrato de Trabajo a Distancia, han sido escasos. En CaAmaño (2010), si bien se comenta el proyecto no se pronuncia respecto de la naturaleza jurídica del concepto. Por otra parte en Feres (2011), se califica al Contrato de Trabajo a Distancia como "una confusa mezcla entre el trabajo a domicilio y teletrabajo". Se estima en contrario, que se debiera optar por en el uso del nuevo término con objeto de favorecer una nueva normativa que logre proteger a ambos colectivos de trabajadores, añadiendo a ello, la posición de relevar del análisis al elemento tecnológico, cuya exaltación no concuerda con una política de mayor tutela a la parte trabajadora.

18 Thibault (2000) p. 42.

19 Ortiz (1996)

20 "El período industrial representaría simplemente una anomalía de 300 años en nuestra historia; nuestra antigua historia laboral nos preparó para el período del centro de trabajo al que estamos llegando ahora y no para el que ahora estamos abandonando". KRAVETZ (1994).

21 Interesante sería realizar un estudio acerca de las ventajas e inconvenientes que trae aparejado la aplicación de un sistema de teletrabajo. En base a lo expuesto en Teletrabajo, una expresión de flexibilidad laboral por Contreras (2001). Ventajas e Inconvenientes al mundo laboral del Teletrabajo. Ventajas: a) Ahorro empresa infraestructura, b) Disminución gasto general de la empresa c) Flexibilidad y Mejora en la calidad de vida. d) Protección del núcleo familiar e) Optimización del tiempo. f) Reducción del tráfico vehicular. Inconvenientes: a) Pérdida de confidencialidad de la información. b) Incremento en costos de equipamiento. c) Pérdida de identidad con empleador. d) Reducción de interacción social. e) Debilitamiento del sindicalismo. 
intensidad del control del empleador podría graduarse en diversos estados ${ }^{22}$. Surge así, el concepto de teledisponibilidad, como la expresión sustantiva en materia de comunicación entre empleador y trabajador ${ }^{23}$. Enseguida, se observó en ella, variadas ventajas, así como inconvenientes.

La complejidad aparente en el análisis de la actividad, determinó que se fueran generando posiciones diversas acerca de la perspectiva que debería adoptar la política legislativa en su tratamiento. Por una parte, hizo pensar a algunos que el teletrabajo debía regirse por un contrato únicamente civil, en base a la inusitada autonomía del trabajador en su ejecución. Otros, ante la masiva aparición de nuevos vínculos de trabajo atípicos, auguraron el término de la subordinación jurídica como elemento tipificador de la relación laboral, ante la supuesta imposibilidad por abarcar modalidades de trabajo lejanas al arquetipo clásico ${ }^{24}$.Más tarde, el desarrollo doctrinal evidenció que el distanciamiento de los sujetos de la relación, no impedía la irrestricta vigencia de la subordinación o dependencia como elemento tipificador, puesto que a través de los medios telemáticos el empleador se vinculaba directamente con el trabajador, aplicando en ello, nuevas herramientas de control, ejerciendo finalmente idéntico poder de dirección. Por consiguiente, tras un nuevo y mejor análisis, se evidenció que la subordinación persistía en las nuevas formas de trabajo, tratándose el teletrabajo de una modalidad distinta pero inmersa dentro del campo de aplicación del mismo derecho del trabajo ${ }^{25}$.

Pese a lo señalado y largamente discutido en foros, el impacto fuera de lo teórico de la modalidad en la práctica de las relaciones laborales no fue el esperado. Muy pocas empresas nacionales adoptaron planes de teletrabajo, limitando las proyecciones iniciales de expansión de la modalidad. En efecto, en constatación de dicha realidad dentro del debate disciplinario, surgieron opiniones que buscaron aterrizar la incidencia de las nuevas tecnologías en las relaciones laborales, existiendo según se dijo, más gente hablando de teletrabajo que teletrabajadores ${ }^{26}$.

Verificada dicha realidad, el tema fue perdiendo terreno en la doctrina, concluyéndose con la vorágine de publicaciones que desató en las décadas pasadas. Sin embargo, la evidencia actual del éxito en la implementación de dicha modalidad en otros países, principalmente europeos, así como la reciente sanción legal en España de la ley RDL 3 /2012 que instaura el Contrato Especial de Trabajo a Distancia, regulando detalladamente la naturaleza jurídica de las labores efectuadas desde el domicilio del trabajador para un empleador; y finalmente un proyecto de ley nacional que regula el contrato de trabajo a distancia ${ }^{27}$, han sin duda revitalizado la temática en el concierto académico del derecho del trabajo, surgiendo nuevas publicaciones ${ }^{28}$.

\footnotetext{
22 No siendo el ánimo de esta monografía realizar un estudio detallado y académico del teletrabajo, las dos clasificaciones más importantes, en tanto derivan de la naturaleza de sus dos elementos más importantes son: 1.-Online: El teletrabajador permanece en permanente contacto con su empleador, no siendo necesaria la posibilidad de un control directo e inmediato sobre su producción en línea. Se distinguen las formas que emplean la teledisponibilidad, esto es, existe un dialogo directo interactivo fluido entre ambas partes a través de medios telemáticos que permiten con control directo sobre su estación de trabajo.

Offline: Bajo esta modalidad el empleador no requiere conexión informática directa con el empleador, salvo las instrucciones iniciales diarias o semanales. Resalta ante todo la importancia del resultado y su análisis, por sobre el desarrollo mismo de la actividad.

$23 \quad$ JURI (2006) p. 98.

24 La discusión doctrinal reseñada se puede conocer en detalle en: CAAMAÑo (2005) pp.25-53.

25 Guajardo (2008).

26 UGARTE (2007) vii p. 180.

27 Cámara de Diputados (2010).

28 Cfr. Caamaño (2010) pp. 79-105.
} 


\section{SITUACIÓN ACTUAL DEL TRABAJO A DISTANCIA}

Ante la escasez de estadísticas en específico, debemos referirnos a la Encuesta Casen de 2009, que recogió cifras respecto de quiénes declaraban ejecutar labores dentro de su vivienda: Hombres 161.343, Mujeres 219.218Total 380.565 (5,73\% de la población ocupada) ${ }^{29}$. Determinándose que al menos un $47 \%$ de dicho grupo trabajaría sin contrato alguno ${ }^{30}$. A partir de dichos datos, se puede constatar la existencia cierta de aquellas personas trabajan fuera de las dependencias empresariales, sin embargo, no existen mayores antecedentes respecto de las circunstancias o condiciones en que se ejecuta dicha actividad y menos aún certeza para inferir si dichos vínculos representan trabajo independiente o subordinado. Sin perjuicio de ello, es factible señalar que representan en número un colectivo importante a estudiar con objeto de emprender próximas modificaciones legales o políticas públicas especializadas.

Luego, también se consultó respecto de quiénes declaraban realizar labores de teletrabajo: del universo de la población activa laboral, sólo 4.784 personas se circunscribieron a la modalidad ocupacional de teletrabajo ${ }^{31}$. No obstante, se desconoce cuál fue el criterio exigido en intensidad en el uso de tecnologías de la informática y comunicación, para discriminar en la calificación del vínculo.

Por consiguiente, pese a la precisión relativa del estudio citado, es posible concluir la existencia de una tímida recepción de la modalidad del trabajo a distancia en nuestro país. Sin embargo, ello no podría llevarnos a desconocer que hoy en día cada vez son más las formas de empleo atípicas, multiplicándose las modalidades del ejercicio de la subordinación jurídica junto con la diversificación fáctica de los indicios tipificadores. Situación en que precisamente ha influido de forma radical la utilización de nuevas tecnologías en el proceso productivo, con el consiguiente impacto en la posibilidad de distanciamiento entre empleador y trabajador.

Bajo dicha consideración, Cristián Salazar, académico de la Universidad Austral, plantea que el trabajo a distancia, se presenta hoy como una favorable alternativa, viable, integral e innovadora para hacer frente a problemáticas como el desempleo, la efectiva integración de discapacitados, de desarrollar la flexibilidad y de integrar a jóvenes, tercera edad y mujeres con hijos al mundo laboral ${ }^{32}$. Secunda dicha posición, Caamaño Rojo que vislumbra en el favorecimiento de un mayor desarrollo la modalidad, un reforzamiento de la real igualdad de oportunidades entre trabajadoras y trabajadores ${ }^{33}$.

Asimismo, desde los postulados de la Responsabilidad Social Empresarial, resulta coherente propender a la multiplicación de vínculos bajo esta modalidad, en sentido de buscar medidas de conciliación entre trabajo, familia y ocio con el objetivo de no sólo de cumplir plenamente las obligaciones jurídicas, sino que asumiendo un rol de compromiso con las relaciones personales de sus trabajadores. ${ }^{34} 35$

\footnotetext{
29 SÁNCHEZ (2012) p. 20, Cuadro 8.

30 El Mercurio Online (2010)

31 SÁNCHEZ (2012) p. 20, Cuadro 9.

32 SALAZAR.

33 Cfr. CaAmaño (2010) pp. 79-105.

34 Sempere y Kahale (2013) p. 113, cita a Libro Verde para Fomentar un Marco Europeo para la responsabilidad social de las empresas. Bruselas. 18 de julio de 2001.

35 El año 2007, la empresa Nestlé Chile fue reconocida entre las empresas más admiradas y con mayor compromiso social corporativo, lo que valió una distinción por parte de la Sociedad de Fomento Fabril. En ello, se consideraron las medidas adoptadas por la empresa, orientadas a conciliar la vida familiar y laboral, como por ejemplo, el retorno gradual de las madres
} 
En consecuencia, sin perjuicio del fracaso de las desmesuradas expectativas generadas en torno al teletrabajo,hoy en día el trabajo a distancia, aparece como una institución de limitada recepción en nuestra masa laboral, que sin embargo, cuenta con un gran potencial de crecimiento.

\section{LEGISLACIÓN APLICABLE Y JURISPRUDENCIA}

El trabajador a domicilio ha sufrido diversos vaivenes en la legislación aplicable. Desde comienzos del Siglo XX, la precariedad del trabajo a domicilio relatada, se encontraba reflejada en la primitiva regulación laboral existente. La ley 4.053 de 1924, excluía al trabajo a domicilio expresamente de las normas de contrato de trabajo.

Más tarde, en el Código del Trabajo de 1931 en su Título II Del Contrato para Obreros, modifico la decisión legislativa, estableciendo un párrafo específico titulado del Trabajo a Domicilio. Obligando al patrón a incorporar al trabajador a un registro especial al efecto, así como la mantención una libreta donde se indicasen las obras realizadas. Regulación bastante avanzada para una época donde la eficacia de la ley laboral era bajísima; lamentablemente no se contaba con el aparato gubernamental necesario para realizar una fiscalización exhaustiva permaneciendo muchas zonas oscuras de precariedad en el ejercicio del trabajo domiciliario ${ }^{36}$. Situación que permanece hasta la actualidad en muchas naciones latinoamericanas, donde pese a contar con un tratamiento legal idóneo, el ejercicio efectivo de la tutela normativa es escaso ${ }^{37}$.

Tras aquella etapa de observancia relativa de la norma de trabajo a domicilio, le siguió una marcada por la desregulación y desatención por parte del Estado. Si bien el DL 2200 de 1978 se estableció su concepto: "Trabajo a domicilio es el que en forma habitual se ejecuta en el propio hogar del trabajador o en lugar libremente elegido por él, sin vigilancia, ni dirección inmediata de la persona por cuenta de quien trabaja, ni de representante suyo", sólo tres años más tarde, la reforma del año 1981 por la ley No 18.018 derogó completamente la normativa de trabajo a domicilio, determinando que no daban origen a contrato de trabajo los servicios prestados en forma habitual en el propio hogar de las personas que los realizan o en un lugar libremente elegido por ellas, sin vigilancia ni dirección inmediata del que contrata. Por cuanto, los trabajadores a distancia de aquel tiempo debían someter su accionar a las normas establecidas en el Código Civil, específicamente a las referidas al contrato de arrendamiento de servicios inmateriales, en los artículos 2006 a 2012 del mismo cuerpo legal.

Al retorno de la democracia, dicha exclusión del ámbito de aplicación de la norma laboral fue maquillada por la ley $\mathrm{N}^{\circ} 19.250$ que elimino la taxatividad del artículo $8^{\circ}$, abriendo una brecha para su reconocimiento legal, al indicar sólo que no hacen presumir la existencia de contrato de trabajo los servicios prestados en forma habitual en el propio hogar de las personas que lo realizan o en un lugar libremente elegidos por ellas, sin vigilancia, ni dirección inmediata del que contrata.

\footnotetext{
con permiso de maternidad y poner en marcha un programa piloto de teletrabajo e incorporó a varios trabajadores discapacitados. MoRales y RomaniK (2011) p. 43.

${ }_{36}$ Código del Trabajo de 1931, Del Contrato para Obreros, VI Del trabajo a domicilio. Artículo 53.- Todo patrón que dé trabajo a domicilio, deberá llevar un registro que se denominará "Registro de Obreros y Salarios a Domicilio", en el que se anotarán el nombre y apellido de los obreros, sus residencias, la cantidad y naturaleza de la obra encomendada y la remuneración que se debe percibir. Artículo 54.- El patrón deberá entregar al obrero que trabaje a domicilio, una libreta en que se indiquen la naturaleza y cantidad de la obra, la fecha en que ésta se encomienda, el precio convenido, el valor de los materiales que se le entreguen y la fecha de la devolución de la obra. La libreta expresará, además las condiciones en que el obrero pagará las pérdidas o deterioros de los objetos que se le confien y el nombre y domicilio del fiador, si lo hubiere.

37 Henríquez (2005) pp. 9-12.
} 
Isaías Rodríguez Reyes / Análisis juridico a la figura del trabajo a distancia

Por consiguiente, se estableció una cuestionable presunción de pertenecer las labores a domicilio a la categoría de los trabajos independientes o por cuenta ajena. Por cuanto, de probarse eventualmente el vínculo de subordinación, superando aquella presunción, se podría constituir una relación de trabajo a distancia como idónea de tutela por la norma laboral.

Posteriormente, la ley 19.759 de 2001 incorporó al trabajo a domicilio a la presunción de laboralidad genérica restableciendo la tutela genérica de la norma laboral sobre las relaciones de trabajo a domicilio. Por otra parte, en materia de jornada se añadió un nuevo reconocimiento a la modalidad en estudio, estableciendo que el personal que trabaje desde el propio hogar o desde un lugar libremente elegido se encuentra excluido de la limitación de jornada. Dicha declaración significa el primer reconocimiento a la figura del teletrabajo por nuestra legislación. Sin embargo, no resulta claro que efectivamente haya otorgado mayor tutela al colectivo de trabajadores a distancia, por el contrario ha sido calificado de poco protector ${ }^{38}$.

Tras dicha reforma, el trabajo a domicilio y teletrabajo conservan en el Código del Trabajo su normativa hasta hoy. La regulación legal actual podría calificarse de insuficiente, por no contar con sanción legal más allá de la citada referencia en materia de jornada.

Luego, bajo una posición tradicional, se podrá sostener que el trabajo a domicilio o a distancia, se trata de una situación que no sin dificultades, podría ser resuelta por nuestra legislación en mera aplicación de reglas generales. En este sentido a partir de la tímida inclusión en materia de jornada, ha llevado a algunos a sostener que contaría con una suerte de régimen laboral específico que despejaría la duda de laboralidad que persiste en otras comunidades jurídicas respecto del ejercicio de dicha modalidad ${ }^{39}$.

Respaldaría ello la escasísima jurisprudencia nacionalal respecto, que ha logrado verificar la existencia de la subordinación y dependencia, al menos en un citado caso, a partir de la observancia de indicios tales como dirección, presencia un programa creado por el empleador y comunicación directa con el trabajador ${ }^{40}$.

Posición que no parecer ser correcta, en tanto, respondería a una concepción limitada que no logra dimensionar la multiplicidad de características en su ejecución cuyos alcances no encuentran respuesta alguna en nuestro Código del Trabajo. Aun cuando es procedente que por nuestra legislación actual, pueda ser considerado un vínculo subordinado de aquellos que tutela nuestro Código del Trabajo, éste carece de la especificidad normativa ${ }^{41}$ y disposiciones que permitan resolver conflictos propios de su ejecución que configuren el sentido y alcance de la figura. Luego, los escasos pronunciamientos de la justicia más que brindar respaldo $u$ otorgarnos siquiera un escenario de relativa estabilidad, abren un espacio a la incertidumbre a la aplicación efectiva de la norma en este tipo de vínculos. Por lo pronto, la solución jurisprudencial no puede detener un análisis de política jurídica que naturalmente trasciende el caso concreto y sus particularidades.

En definitiva, se estima que el Código del Trabajo carece hoy del tratamiento necesario que brinde contenido a los derechos a tutelar, pudiendo cuestionarse que efectivamente nuestro cuerpo legal haya resuelto de forma definitiva los cuestionamientos respecto de laboralidad que pesan sobre la figura, máxime si se considera el arraigo de la (supuesta) autonomía que rige en la práctica jurídica respecto de las labores que se ejecutan desde el propio hogar.

8 GaMONAL (2010) p. 43.

39 Ugarte (2007) vii pp. 193-194.

10 Ugarte (2007) vii p. 190.

4l CaAmaño (2010) pp. 11-14. 
Carencias que han motivado incluso, un último intento por legislar acerca del tema, por iniciativa del Ejecutivo del 20 de agosto del 2010, mediante la cual se presentó proyecto de ley al respecto ${ }^{42}$. En Mensaje No224-558 se estableció el convencimiento que nuestra legislación se encuentra objetivamente atrasada frente a la realidad que presenta el mercado laboral nacional respecto del trabajo a domicilio. En referencia a los beneficios del trabajo a distancia para el país, se trazó como objetivo una ley que vaya en su decidido fomento. El proyecto se tituló "que regula el contrato de Trabajo a Distancia". Contiene tras la Indicación No 614-358 la cantidad de 10 artículos. Numerales todos a integrarse desde el artículo 86 bis - A y sgtes.

Ingresó a la Comisión de Trabajo y Legislación, donde en sesión de noviembre del 2010 se acordó respecto de la necesidad de votar en general el proyecto de esta sesión; aprobándose con 12 votos a favor y una abstención.

El Ejecutivo en cumplimiento presentó indicaciones fruto de los comentarios recibidos, mediante indicación No 614-358 del 1 de marzo del 2011. Sin embargo, a la presente fecha el proyecto permanece detenido en su tramitación.

\section{DERECHO COMPARADO}

Bajo el propósito de ilustrar las contundentes diferencias en lo referente a implementación, desarrollo y legislación existente sobre trabajo a distancia, se ilustrará el escenario normativo actual de la Organización Internacional del Trabajo, Unión Europea y España al respecto:

\section{$6.1 \mathrm{OIT}$}

La Organización Internacional del Trabajo ha presentado siempre interés en la amplia gama de temáticas que circundan al mundo laboral, no siendo la excepción el trabajo a domicilio. Inmerso dentro de auge iuslaboralista de los 90' por el teletrabajo, el año 1996 convocada en Ginebra el 4 de junio de 1996, emite el Convenio $\mathrm{N}^{\circ} 177$ y Recomendación $\mathrm{N}^{\circ} 184$ sobre Trabajo a Domicilio. Instrumentos no ratificados ni implementados por nuestra legislación hasta el día de hoy.

La expresión trabajo a domicilio fue definida, distinguiéndolo expresamente del trabajo independiente, entendiendo por tal la que se ejecute con el grado de autonomía y de independencia económica necesario en virtud de lo que disponga la legislación del país que suscribe. Abunda el convenio también en subrayar la igualdad de trato que se pretende respecto del colectivo de trabajadores a domicilio, especialmente en lo que refiere en materias de seguridad y salud, remuneración, derecho de sindicación y seguridad social ${ }^{43}$.

\subsection{Unión Europea}

De acuerdo a cifras mediamente recientes, en la Unión Europea conviven en torno a 21 millones de teletrabajadores, que representan un $13 \%$ de la población ocupada ${ }^{44}$. Aun cuando muchos efectúan labores por cuenta ajena, dicho indicador es síntoma de un cambio incipiente pero progresivo en el modo de ejecución de la actividad laborativa.

\footnotetext{
12 Existía un proyecto de ley previo de fecha martes 05 de diciembre de 2006, $\mathrm{N}^{\circ} 4712-13$, que modifica el Código del Trabajo, regulando el contrato de teletrabajo. Nunca fue discutido por la Comisión de la Cámara de Trabajo y Seguridad Social.

43 Organización Internacional del Trabajo (1996).

44 Sempere y Kahale (2013) p. 20.
} 
Isaías Rodríguez Reyes / Análisis juridico a la figura del trabajo a distancia

Fruto de similar análisis, a partir de la Cumbre de Lisboa del año 2000, en el contexto de la Estrategia Europea de Empleo, el Consejo Europeo invitó a interlocutores sociales a negociar acuerdos de trabajo flexible, con el objeto de mejorar la productividad y la competitividad de las empresas ${ }^{45}$. En razón de aquello, con fecha de 23 de mayo de 2002 se aprobó el Acuerdo Marco Europeo sobre Teletrabajo, que fue firmado con fecha de 16 de julio del mismo año en Bruselas por la CES- Confederación Europea de Sindicatos y Organizaciones Patronales Unión Europea ${ }^{46}$. En dicha instancia se consideró que el nuevo trabajo a domicilio con la implementación de las TIC, resulta ser un medio de modernización de la organización del trabajo para las empresas y organizaciones de servicios públicos, y para los trabajadores, significa reconciliar la vida profesional y vida social, proveyendo de una mayor autonomía en la realización de sus tareas ${ }^{47}$. Los partícipes trazaron como objetivo mantener a la par la flexibilidad y seguridad, que sea mejorada la calidad del empleo y que las personas con discapacidades tengan mejor acceso al mercado de trabajo.

El Acuerdo se pronuncia respecto de la definición y ámbito de aplicación del teletrabajo, la naturaleza voluntaria de su implementación en las empresas, las condiciones de empleo, la política de protección de datos, la regulación de la vida privada del teletrabajador, las cuestiones relativas a los equipamientos de trabajo, la salud y seguridad del teletrabajador, la organización del trabajo, la formación, los derechos colectivos de los teletrabajadores, y por último la puesta en marcha y el seguimiento en la aplicación de los principios pactados en el texto del acuerdo.

\subsection{EsPaña}

El Estatuto de los Trabajadores, en su artículo 13, vino regulando, desde su originaria versión de 1980, el trabajo prestado a domicilio, entendiendo por tal aquel realizado en un ámbito no controlado por el empleador ${ }^{48}$. Contrato de trabajo a domicilio se consideró aquel en que la prestación de la actividad laboral se realice en el domicilio del trabajador o en el lugar libremente elegido por éste y sin la vigilancia del empresario. Última característica que generaba discusión respecto de su concordancia con actividades que implicaban teledisponibilidad donde resultaba ciertamente discutible que no existiera verdadera vigilancia ${ }^{49}$.

En dichos términos se mantuvo la regulación hasta que la reforma laboral de 2012 incorporó el llamado Trabajo a Distancia, apuntando a introducir la figura del teletrabajo, cuyos alcances no habían quedado del todo comprendidos en la normativa anterior. Mediante el artículo 6 de la L3/2012 se modifica el título del artículo 13 del ET por "trabajo a distancia": "Tendrá la consideración de trabajo a distancia aquél en que la prestación de la actividad laboral se realice de manera preponderante en el domicilio del trabajador o en el lugar libremente elegido por éste, de modo alternativo a su desarrollo presencial en el centro de trabajo de la empresa". La doctrina española entendió que aún sin aludirlo por su nombre más usual, el teletrabajo desplazaba a la actividad a domicilio como enfoque de la normativa ad-hoc ${ }^{50}$.

En dicha iniciativa se expresó el deseo de promover nuevas formas de desarrollo de la actividad laboral que encajen perfectamente en el modelo productivo, favorecer la flexibilidad de las

\footnotetext{
45 Confederación Europea de Sindicatos y Organizaciones Patronales Europea (2002)

46 Confederación Europea de Sindicatos y Organizaciones Patronales Europea (2002).

47 Confederación Europea de Sindicatos y Organizaciones Patronales Europea (2002)

48 Sempere y Kahale (2013) p. 9.

49 Cfr. Thibault (2000).

50 Sempere y Kahale (2013) p. 9.
} 
empresas en la organización del trabajo, incrementar las oportunidades de empleo y optimizar la relación entre trabajo y vida personal y familiar.

Previo al reciente desarrollo legal, existen antecedentes del año 2003 de regulación por acuerdos marcos sindicales, tanto a nivel europeo como a nivel de confederaciones sindicales.

Entre las regulaciones más recientes, se encuentra el Acuerdo para el Empleo y la Negociación Colectiva 2012, 2013 y 2014. Manteniendo los criterios de acuerdos anteriores, señala los tres criterios base que pueden ser utilizados por las empresas y por los trabajadores y sus representantes como base para mantener equilibrio entre flexibilidad y seguridad:

a) El carácter voluntario y reversible del teletrabajo, tanto para el trabajador como para la empresa.

b) La igualdad de derechos, legales y convencionales, de los teletrabajadores respecto a los trabajadores comparables que trabajan en instalaciones de la empresa.

c) La conveniencia de que se regulen aspectos como la privacidad, la confidencialidad, la prevención de riesgos, las instalaciones, la formación, entre otros.

Por otra parte, el trabajo a distancia también ha tenido un fecundo desarrollo en la administración pública española. La Orden Ministerial APU/1981/2006, promueve la implantación de programas piloto de teletrabajo en los departamentos ministeriales, disponiendo que los organismos públicos deberán oir en dicho proceso a las organizaciones sindicales respectivas. Recalca asimismo, que la participación de los funcionarios públicos en dicho proceso, tendrá siempre el carácter de voluntario. Aquella normativa se enmarcó, dentro de un Plan -macro español denominado Concilia, que apunta a la conciliación de la vida personal con la laboral en la Administración General del Estado ${ }^{51}$.

\section{ANÁLISIS JURÍDICO}

Bajo el propósito posterior de refrendar la necesidad de una legislación sobre el tema, se estima adecuado efectuar un análisis de cada una de las instituciones laborales ysu grado de impacto en la figura del trabajo a distancia. Así, en base a los defectos particulares en cada punto, es posible encaminar una propuesta normativa a partir del tratamiento pormenorizado de la modalidad en análisis.

\subsection{TRABAjo A DOMICILIO AUTÓNOMO}

Calificado constantemente dentro de la llamada zona gris de imputación de la norma laboral, la problemática de definir la naturaleza jurídica del trabajo realizado en el domicilio, es un punto que siempre ha desincentivado la posibilidad de incorporar una regulación ad-hoc a la actividad. Luego, por las características intrínsecas a la labor a distancia, resulta absolutamente comprensible una tendencia a vincular de forma naturaldichas actividades con el trabajo independiente ${ }^{52}$.

En efecto, existen muchos casos donde el trabajo realizado en el domicilio será genuinamente autónomo, por ende, no dependiente de empleador alguno. En aquellas labores será el mismo actor quién disponga de plena autonomía en la organización de la actividad económica,

51 Sempere y Kahale (2013) p. 55.

52 Morales y Romanik (2011) p. 58. 
Isaías Rodríguez Reyes / Análisis juridico a la figura del trabajo a distancia

con la consiguiente reversión en beneficio propio de la utilidad económica de la actividad ${ }^{53}$. Podrá libremente aceptar o rechazar los encargos que distintas empresas le requieran, negociando efectivamente las cifras de cada proyecto a realizar. Dichas labores necesariamente corresponde que sean reguladas por instituciones del derecho civil, no siendo susceptibles de protección por la norma del derecho del trabajo.

Sin embargo, el análisis exige superar la idílica imagen estereotipada de un trabajador libre de directrices, aparentemente autónoma por no contar con la presencia ni control inmediato de nadie $^{54}$. Como se viene sosteniendo, no todos los trabajadores a domicilio representan verdaderos trabajos independientes. La ausencia, en principio, del característico indicio de la vigilancia inmediata, genera vínculos de subordinación atenuados en contraste con la relación de trabajo típica. Luego, ello no significará la imposibilidad que muchos vínculos efectivamente reúnan una serie de indicios de subordinación que configuren una relación laboral conforme al artículo $7^{\circ}$ del CT. La subordinación, ahora teñida de modernidad y sometida a nuevas exigencias, continúa siendo, superadas las críticas e incertidumbre ${ }^{55}$, el criterio idóneo para la calificación jurídica de la necesidad de tutela de la norma laboral. Como sabemos, la subordinación refiere a la inserción del trabajador dentro del ámbito de organización y dirección de la empresa ${ }^{56}$, por tanto si se efectúa el análisis respecto de las labores a domicilio podría establecerse su presencia de conformidad a los siguientes indicios: a) Sujeción a las directrices y control empresarial, b) Facultad de determinar programa informático específico de comunicación o desarrollo de labores, c) Frecuencia de la comunicación con el empleador a través de medios informáticos, d) Libertad horaria en la ejecución y entrega de las tareas. e) Obligación y frecuencia de asistencia a la empresa a reuniones de planificación, f) Exclusividad en la prestación de sèrvicios para un mismo empresario, g) Ajenidad en la titularidad directa de los frutos o utilidades que genere la prestación del servicio, h) Elección del lugar de la prestación: domicilio o telecentro. I) Control enfocado en el proceso y generación del producto, o sólo en su resultado.

En consecuencia, como se observa la distancia del trabajador con el empleador, no implicará, conforme ha insistido la doctrina iuslaboralista, que el vínculo no pueda reunir los requisitos de imputación básicos de la norma del derecho del trabajo ${ }^{57}$. Pudiendo existir vínculos laborales de subordinación incluso aún más intensa que en relaciones de trabajo típicas, especialmente en lo que refiere a la presencia de la teledisponibilidad y el control constante que trae aparejado en su ejecución.

Comprendido aquello, resulta necesario reconocer que la diferencia de trabajo a domicilio autónomo con el trabajo a domicilio deṕendiente, será en muchos escenariosuna labor de compleja determinación. Sin perjuicio de ello, la constatación de dicha realidad no puede servir de fundamento para perseveraren la desregulación normativa, en tanto, la ausencia de norma expresa que lo sancione, favorecerá la multiplicación de vínculos laborales reales con garantías inferiores a los mínimos legales. La generación de trabajo autónomo, podría corresponder, como algunos han señalado, a meras estrategias de huida del derecho del trabajo y la búsqueda consecuente de disminución de costos para la empresa ${ }^{58}$.

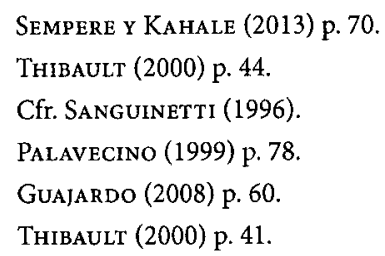




\subsection{TÉCNICA LEGISLATIVA}

Debe concederse que las características propias de la evolución de diversas áreas de la actividad laborativa, han hecho exigibles variadas regulaciones especiales en nuestro Código del Trabajo. En efecto, con objeto de cubrir las innumerables manifestaciones del régimen de subordinación, cuyas particularidades no se encontraban enteramente previstas en la normativa común, se han ido generando por nuestra legislación una serie de contratos de trabajo especiales. Así, nuestro Código del Trabajo ha sido objeto reciente de sucesivas adiciones en el Titulo de los Contratos Especiales, normándose estatutos particularizados a determinados colectivos de trabajadores. Ejemplo de ello son los trabajadores de artes y espectáculos, los tripulantes de vuelo o los deportistas. Reveladores todos de una tendencia que ha impactado al Código del Trabajo, cuyo articulado pese a mantener la coherencia interna del Código original, amenaza con seguir abultándose con nuevos colectivos que exigen atención ${ }^{59}$.

En este sentido, se entiende que con motivo del trabajo a distancia, nuestra legislación laboral debe recoger dichas particularidades, actuando en promoción y protección de dicha actividad y terminando con la pretendida rigidez que supone que a una forma de ejecución del trabajo tan radicalmente singular, sólo le pueda ser factible aplicar una regulación plural y genérica. Por el contrario, si el inmovilismo de nuestra legislación laboral perdura, el único escenario posible es una profundización de la precarización de las formas de trabajo atípicas.

En esta oportunidad con objeto de proponer una legislación acerca del fenómeno del trabajo a domicilio o a distancia, se busca insistir en la adición de un nuevo contrato especial. Tal cual sostuvo el congelado proyecto $\mathrm{N}^{\circ} 224-558$, su articulado se debiera alojar precisamente en el mismo Título de los Contratos Especiales, a través de una serie de numerales a incorporar en el artículo 86.

La aplicación de la referida técnica legislativa en esta materia surge de la idea de congeniar las exigencias básicas de la protección laboral con la flexibilidad de los elementos clásicos que trae aparejado el trabajo a distancia. Cuestión sincerada en el mensaje del Ejecutivo que presenta el proyecto que sin embargo, anticipa constituirá una difícil tarea dado el amplio objeto de aplicación determinado. En efecto, lejos de tratarse de un colectivo homogéneo cuyas prácticas y condiciones son similares, como los trabajadores de artes, deportistas o agrícolas, encontramos trabajadores a distancia o a domicilio en una amplia diversidad de actividades.

\subsection{Definición}

La primera precisión a efectuar al respecto, resulta del hecho que el trabajo a distancia en sí mismo no vincula propiamente a un colectivo de trabajadores, sino más bien a una forma de desarrollo de la actividad laborativa cuya adopción puede ser propia de un grupo de trabajadores con intereses, cargos y funciones absolutamente disímiles. La labor legislativa a la hora de precisar el grupo objetivo para el cual se legisla, deberá tener presente la particular característica del trabajo a domicilio, según la cual los efectos positivos tienden acentuarse más en los profesionales de alta calificación, mientras que los negativos aparecen con mayor frecuencia en los trabajadores

\footnotetext{
59 Con fecha 26 de abril de 2012, se presentó ante la Comisión de Trabajo y Seguridad Social del Senado, proyecto de ley que regula la labor de teleoperadores de call center, a través del contrato de teleoperadores. Informes de Proyecto de Ley Cámara de Diputados $\mathrm{N}^{\circ}$ Boletín $\mathrm{N}^{\circ} 8.263-13$.
} 
Isaías Rodríguez Reyes / Análisis juridico a la figura del trabajo a distancia

menos calificados ${ }^{60}$. De esta manera, si bien la técnica del estatuto o contratos especiales ha sido la escogida por la experiencia comparada para legislar sobre el tema, se debe subrayar que el trabajo a distancia no se circunscribe simplemente a un formato único de contrato.

\subsection{LUGAR}

Elemento de la esencia del sistema de trabajo en análisis, por cuanto, resulta necesario que la ley exija su precisión en cada uno de los contratos a estipular.

Por regla general bajo éste régimen el trabajo se ejecutará en el hogar/domicilio del trabajador. Sin embargo, no debiese resultar imprescindible que el domicilio fijado sea el hogar del trabajador, en tanto, puede obrar como lugar de la prestación de servicios un lugar libremente elegido por las partes contratantes. Por consiguiente, sólo debiese bastar con que fuese un lugar distinto del domicilio legal de la empresa. En otros países, existen los llamados centros de teletrabajo o telecottages, que se definen como establecimientos que ofrecen puestos de trabajo a empleados de una o más organizaciones, o servicios telemáticos a clientes remotos ${ }^{61}$. Aun no contándose con información de iniciativas en ese sentido en nuestro país, no se ven razones para que la futura regulación límite a la concepción de teletrabajo en su dimensión individual, y desconozca su dimensión colectiva.

\subsubsection{Determinación del lugar}

El traslado del elemento locativo del poder de dirección del empleador al ámbito de decisión del trabajador, sin duda distingue a este contrato especial. Porque aun cuando pueda ser un elemento a determinar por las partes en la suscripción del contrato, resulta de la esencia de la figura que sea el trabajador quién libremente señale el lugar en que prestará servicios para su contratante. Punto que manifiesta plena concordancia con el carácter voluntario para el trabajador de la implantación de la presente modalidad de trabajo.

En este sentido, surge la interrogante sobre si el trabajador, tras la suscripción del contrato de trabajo, podría modificar con posterioridad el lugar de prestación de servicios. A lo que debiéramos concluir la procedencia legal de cualquier cambio mientras la voluntad del mismo resida en el trabajador. Principalmente, en razón de los fundamentos de la figura que han buscado siempre una óptima conciliación de la vida familiar con la vida laboral; finalidades que se perderían si fuese el empleador quién acerca de su ubicación y traslado.

\subsubsection{Ejercicio del ius variandi respecto del lugar de prestación de servicios}

En una futura normativa del colectivo de trabajadores a distancia no debiese ser posible ejercer por parte del empleador la facultad del ius variandi (art.12) en lo referente al lugar de prestación de servicios. Me mueve a tal conclusión, lo esencial en la figura del trabajo a distancia que resulta ser, el poder de decisión al trabajador sobre la determinación del lugar. De todas las definiciones observadas de la figura queda absolutamente claro que su determinación se hará libremente por el trabajador, bajo ningún tipo de excepción. Luego, las razones que impulsan a legislar

60 Thibault (2000) p. 112.

61 Centro de Investigación y Documentación del Ministerio de Trabajo y Asuntos Sociales (2000) p. 25. 
sobre la figura del teletrabajo, tienen sustento en una serie de propósitos sociales y políticos cuyo alcance de ningún modo pudiera lograrse si el empleador pudiese vulnerar su elemento esencial.

En consecuencia, puede concluirse que la facultad de alterar unilateralmente el contrato por parte del empleador respecto del lugar de prestación de servicios, debería ser improcedente de ejercer, dada la existencia de un contrapeso legal suficiente de decisión y/o variación radicado en la contraparte débil de la relación.

\subsection{JORNADA}

El trabajo a distancia plantea el cuestionamiento acerca de si quiénes trabajen bajo esta modalidad deberían estar sometidos a jornada. Dicha situación fue resuelta por nuestra legislación, precisamente en una de las escasas referencias al trabajo a domicilio y teletrabajo que tiene nuestro Código del Trabajo, determinando que tanto quiénes trabajen en su propio domicilio o ejecuten teletrabajo, se encontrarán exentos de limitación de jornada.

Si bien pudiesen existir aprensiones respecto modalidades de trabajo que impliquen trabajo más allá de los límites máximos horarios legales ${ }^{62}$, es del caso señalar, que una de las grandes ventajas que importa para el trabajador la decisión de teletrabajar es obtener una mayor libertad en cuanto a la distribución de jornada, por cuanto someter a control o fiscalización esta variable quizás eliminaría sus incentivos naturales propios. Sin embargo, parece ser necesario que sólo en los casos que la ejecución implique teledisponibilidad, es decir, labores que exijan al trabajador, entre determinados periodos horarios, estar vinculados vía informática directa e ininterrumpida con el empleador, como por ejemplo resultarían labores de tele operador. En este ámbito de casos resulta imprescindible que permanezca la limitación de jornada semanal de 45 horas, evitando que a través de la vía del trabajo a distancia se logre eludir el cumplimiento del espíritu de la norma laboral.

En este sentido, particular es el caso del proyecto de ley anteriormente referido, que en este punto, en primer término coordinó este contrato de especial con la única referencia en nuestro Código actual al teletrabajo, esto es, su exclusión de la limitación de jornada: Artículo 86 bis D.Los trabajadores cuyos contratos se rijan por el presente Capítulo, estarán excluidos de la limitación de jornada prevista en el inciso primero del artículo 22 de este Código. Sin embargo, por Indicación al Proyecto de Ley por parte del Ministerio del Trabajo del 1 de marzo del año $2011^{63}$, se propuso normar la jornada de quiénes por medios informáticos deben permanecer disponibles durante un espacio de horas. Agregación necesaria al proyecto, en tanto se trata de una modalidad bastante intensa de subordinación que en nada difiere de una ejecución de la actividad laborativa presencial o en las dependencias de la empresa, por el contrario el nivel de sujeción del trabajador al poder de dirección y mando del empleador puede ser más intenso.

\footnotetext{
62 A partir de la ley 19.759 , se sostuvo que precarizaba aún más la situación legal de los teletrabajadores al no hacerles aplicable el límite de la duración máxima de la jornada de trabajo, los excluye del control de asistencia o de la posibilidad de pactar jornada extraordinaria. Gamonal (2010) p. 43.

${ }_{63}$ Especialmente atingente es la obligatoriedad del registro de la conexión al sistema por parte del trabajador. Asimilable a la asistencia, manifiesta un reconocimiento a la equiparidad en el ejercicio de la subordinación con el ejercicio clásico de la relación laboral. Consolidando una norma tutelar que se hace cargo de la protección del trabajador a distancia en la ejecución de la actividad laborativa desde su hogar. Interesante sería añadir la precisión de los medios de control a utilizar, tal cual proponía el profesor Juri Sabag muchos años antes del presente proyecto. Por cuanto, dentro de la despliegue de un sistema informático, podrían existir no sólo un sistema de control como estar conectado o no, sino intensidad del trabajo, número de ventanas desplegadas, detalle de historial de navegación, registro de correos y comunicaciones con la empresa por mensajería instantánea, etc. Puesto que su aplicación intensiva podría lesionar la garantía de la intimidad del trabajador quién podría ser observado incluso en su uso recreativo del PC, aún fuera de los tiempos de trabajo.
} 
Isaías Rodríguez Reyes / Análisis juridico a la figura del trabajo a distancia

En este sentido, realizar distinción respecto del colectivo de trabajadores sujetos a teledisponibilidad parece ser una medida correcta, en atención a la necesaria tutela de la norma frente a una situación de control sistemático en línea. Consideraciones que no compartirían otros trabajadores a distancia con actividades que sólo requieren de la entrega de resultados específicos diarios o semanales, no siendo en ellos necesaria una regulación en materia de distribución de jornada.

\subsection{DeTERMiNACión DE LA PROPIEDAD DE LOS EQUipos Y MATERLALES CON LOS QUE SE PRESTARÁN LOS SERVICIOS PACTADOS}

Respecto a la presente consideración, no debemos olvidar que bajo el régimen de aplicación general, es el empleador quién tiene la obligación de proporcionar los medios para la realización del trabajo, por cuanto no asistiendo la voluntad del trabajador de facilitar la utilización de un equipo de su propiedad para la realización del trabajo, deberá ser la empresa la que debiera necesariamente deberá concurrir a ello.

En efecto, se sostiene que dicho punto corresponderá que la ley atribuya la responsabilidad al empleador. Por el contrario, establecer el libre pacto de las partes, atribuiría una naturaleza distinta de la norma laboral al suponer la equidad de los contratantes en la suscripción del contrato, característica impropia de conformidad a los principios más básicos del derecho del trabajo. Marcando una eventual injusticia proveniente de la norma, por cuanto se podría constituir como una barrera de entrada al mundo del trabajo la posesión de ciertos bienes o herramientas para el desempeño del mismo. Dificultando el acceso al mundo laboral de quiénes poseyendo los estudios, habilidades y capacidades afines, no cuentan con los materiales idóneos. Por consiguiente, sería preferible un pronunciamiento claro respecto de la obligación de su aporte, recordando que el foco de cualquier legislación debiese estar dirigido siempre en el trabajador de menor calificación e ingresos, en tanto, es quién requerirá de forma efectiva y en mayor medida, la tutela de la norma del Código del Trabajo.

\subsection{GASTOS, COSTOS DE OPERACIÓN Y REPARACIÓN}

A diferencia de los equipos o implementos que eventualmente el trabajador pudiese poseer, los costos, sin lugar a dudas, deben ser necesariamente de cargo del empleador. Establecer el libre pacto en este aspecto, podría eventualmente significar una pérdida de la remuneración final por parte del trabajador, cuestión que entraría en franca contradicción evidente con uno de los pilares más básicos de la relación laboral: la ajenidad. Principio que se desarrolla en el plano de las relaciones patrimoniales que fluyen en razón del contrato de trabajo, por el cual un trabajador no tendrá derecho a percibir los frutos / utilidades que el negocio importe directamente, sino que sólo mantendrá su derecho a la remuneración en función a la actividad laborativa realizada. Como contrapartida a ello, es que sobre el empleador recae el riesgo de la empresa, vale decir tanto el resultado económicamente adverso como el favorable le será de su exclusivo cargo ${ }^{64}$. Lo que se podría resumir en que el trabajador no trabaja para apropiarse de la utilidad de su trabajo sino para percibir una retribución específica por el servicio prestado ${ }^{65}$.

\footnotetext{
gi Thayer y Novoa (2006) p. 234.

65 LÓPEZ (2004) p. 106.
} 
Imaginar un teleoperador que contratado por la remuneración mínima por un contrato de trabajo a distancia, deba por "acuerdo" con el empleador solventar los gastos operacionales que requiriese en su domicilio en razón del trabajo, refleja una situación de inequidad patente que debiese ser prevista y evitada por la futura ley. La irrenunciabilidad de los aspectos más básicos de la relación laboral, debe ser cautelosamente abordada en las sucesivas y necesarias reformas a realizar en nuestro Código respecto de formas de trabajo fronterizas o atípicas, debiendo prevalecer siempre la naturaleza tuitiva o protectora de la norma laboral. Independiente que el grupo objetivo mayoritario de esta modalidad de trabajo pueda referir a profesionales y personal calificado o sin fiscalización superior inmediata, nada impide que se adopte dicha modalidad en personal de menor calificación e ingresos, donde la subordinación naturalmente es más intensa; situación donde se volvería un verdadero abuso el pacto libre del traslado de los costos a la parte más débil de la relación.

Sería positivo que la futura regulación supusiera que será el empleador el responsable de los gastos y costos de operación como corresponde a una relación de subordinación y dependencia donde los beneficios y pérdidas de la actividad laborativa pertenecen a la parte empresaria, en tanto, es la asunción del referido riesgo o responsabilidad por parte de la entidad empleadora que permite distinguir con nitidez el contrato de trabajo de figuras civiles o comerciales, que nada se condicen con la relación que regula el Código del Trabajo.

\subsection{Teletrabajo parcial}

Interesante es tener consideración en una próxima reforma a nuestro Código del Trabajo, la modalidad de implementación parcial que ha encontrado esta figura en el derecho comparado español. Especialmente el caso de la empresa española Repsol que representa un ejemplo de éxito en la implantación de programas de teletrabajo, a tal punto que en el año 2012 elaboró una guía empresarial para la implementación de trabajo a domicilio con señalamiento de útiles recomendaciones a partir de la experiencia de aquel Departamento de Recursos Humanos ${ }^{66}$. Dentro de las sugerencias señaladas se encuentra precisamente que el teletrabajo sólo pueda ejecutarse a tiempo parcial para garantizar la vinculación con el entorno habitual de trabajo, con ello se busca subrayar que el trabajo a distancia sea una modalidad voluntaria y reversible. Punto que parece ser razonable incorporar en la conformación de un futuro, máxime si consideramos la tímida recepción y falta de incentivos del mundo empresarial nacional respecto de la figura.

En este sentido, el proyecto de ley No224-558 de reciente referencia, establece como una de sus normas más innovadoras, el establecimiento de una modalidad alternativa de trabajo a domicilio dirigida a trabajadores que han suscrito contrato de acuerdo a las reglas generales. Señala el artículo 86 bis $\mathrm{E}$ del proyecto:

"Aquellos trabajadores que presten sus servicios en la empresa, cumpliendo jornadas de trabajo de conformidad a las reglas generales, podrán pactar con sus empleadores, temporal o permanentemente, que dichos servicios puedan desarrollarse de acuerdo a la modalidad señalada en el inciso primero del artículo 86 bis, dejándose constancia de dicho acuerdo en un anexo del contrato de trabajo. Para éstos efectos, las partes podrán establecer alternativas de distribución de días dentro de la semana, o de horas dentro de uno o más días. En estos casos

66 RePSOL (2012). 
Isaías Rodriguez Reyes / Análisis juridico a la figura del trabajo a distancia

la jornada de trabajo pactada se determinará proporcionalmente, considerando exclusivamente el tiempo de prestación de servicios en la empresa."

Esta disposición propone una modificación voluntaria y alternativa de la distribución de jornada, como vía de fomento al desarrollo de la modalidad de trabajo a distancia en la planta de trabajadores. Se consolida así, como una atractiva vía mediante la cual el empleador puede mantener la productividad de su empresa, cuando por diversos motivos sea necesario o deseado por el trabajador permanecer en su hogar durante un espacio de tiempo. No obstante, ser medianamente factible adoptar esta medida bajo nuestra legislación vigente, se evidencia un decidido fomento de la modalidad por esta vía que subraya el concurso de voluntades de las partes. Asimismo, representa una práctica inmersa dentro de las llamadas políticas de flexibilidad laboral, cuya implementación no representa detrimento o precarización alguna de las garantías del trabajador.

\subsection{Estipulaciones previstas en el artículo io del Código del Trabajo}

El artículo 10 del Código del Trabajo que señala las estipulaciones mínimas del contrato de trabajo, es insuficiente a la hora de abordar el fenómeno del trabajo a distancia. Cualquier proyecto que busque dar tratamiento legal a la figura en análisis debe exigir pronunciamiento específcos en las materias insignes y determinantes de la modalidad, como las anteriormente reseñadas: lugar, herramientas y costos. Sin perjuicio de ello, se estima necesario tener presente además las siguientes consideraciones.

\subsubsection{Determinación precisa de la naturaleza de los servicios}

Al existir en principio, menor control sobre la forma en que el trabajador desempeñará cada una de la actividades que se le encomienden, estimo la precisión y detalle sobre las funciones o servicios a desempeñar debe ser aún mayor en la estipulación de un futuro contrato en la materia. Su pacto expreso ayudaría a evitar conflictos innecesarios que provienen únicamente de la falta de una acertada comunicación de las partes.

\subsubsection{Remuneración}

Esta modalidad de trabajo, en estricto cumplimiento de los señalado por el Convenio $\mathrm{N}^{\circ} 177$ de la OIT, no debiese significar disminución de la remuneración de quiénes decidan trabajar desde su domicilio. Los resultados de la actividad laborativa no tendrían por qué representar menores réditos para la entidad empleadora que justificasen una reducción en el monto de la remuneración. No podría una empresa a través de la suscripción de sucesivos de contratos de trabajo a distancia generar un personal con profundas diferencias entre trabajadores de planta y trabajadores a distancia. Como insistiré, la generación de esta nueva forma de contratación no debiera implicar una precarización de las condiciones laborales de los trabajadores, por cuanto si bien la asignación de movilización pudiese disminuir, la labor y contraprestación debiese ser idéntica sustancialmente respecto de quiénes laboren presencialmente. 


\subsubsection{Demás pactos que acordaren las partes}

Manteniendo esta modalidad una numerosa cantidad de consideraciones desconocidas al modelo típico de relación laboral, serán muchísimos pactos posibles los que podrán anexarse al contrato de trabajo, tales como:

a) Asignación de Movilización: Presenta la particularidad que si bien el trabajador requerirá asistir a la empresa con motivo de reuniones de planificación o evaluación, la cantidad de la asignación podrá ser razonablemente menor a la genérica del resto de la planta de trabajadores.

b) Clausula de dedicación exclusiva ${ }^{67}$ : En razón del tiempo disponible, se intenta restringir que el trabajador dedique su tiempo a otro empleador, puesto que se desnaturalizaría la función de esta modalidad de trabajo si estuviese obligado por simultáneamente a numerosos contratos de trabajo a distancia. Como contrapartida se adscribe a que la asunción de dicho pacto, debiese significar un el devengamiento de un incentivo remuneratorio adicional.

c) Seguridad de datos: Enumerado siempre dentro de los aspectos negativos de la implementación de un sistema de trabajo a domicilio ${ }^{68}$, es indesmentible que implicará mayores riesgos para la seguridad comercial de la empresa, puesto que pierde el control físico de los datos. Por consiguiente, es recomendable que la adopción de cualquier medida de control informática deba quedar estipulada previa al inicio de la relación laboral, mediando en ella un estricto cumplimiento a la garantía de privacidad e intimidad de los trabajadores ${ }^{69}$.

\subsection{VISITAS DEL EMPLEADOR}

Deberá la futura legislación ad-hoc contemplar regulación acerca de visitas del empleador al domicilio del trabajador. Se extraña que en el proyecto de anterior referencia, en nada se haya abundado al respecto. Se entiende que en el desarrollo de la actividad de trabajo a distancia las instancias de visitas se harán necesarias, por ejemplo, con motivo de la revisión, implementación o mantención de medios necesarios o para la preparación del lugar donde se realizará la prestación a favor del empleador.

Su regulación se encuentra plenamente justificada, por cuanto la libre autonomía de las partes en esta materia, podría redundar en un pacto indiscriminado que representaría un claro caso de colisión entre el derecho fundamental a la intimidad con el derecho a ejercer una actividad comercial. Es deber de la norma laboral la protección y resguardo de las garantías constitucionales específicas como inespecíficas de los trabajadores, siendo natural una prevención en tal sentido.

\subsection{Higiene y Seguridad}

Se puede anticipar una menor exigibilidad en materia de higiene y seguridad que la norma laboral debiese imponer al empleador, en conocimiento que la actividad laborativa se ejecutará apartada del control diario empresarial. Siendo difuso poder distinguir que corresponderá a un accidente laboral o doméstico, por ende, parece ser razonable extender una menor responsabilidad.

\footnotetext{
JURI (2006) p. 101.

Contreras (2001) pp. 40-48.

69 Lizama (2004) pp. 203-216.
} 
Sin embargo, es necesario insistir en la necesidad de propender por una mayor exigibilidad en materia de higiene y seguridad, no debiendo per se el contrato a distancia significar un traslado absoluto de responsabilidades del empleador al trabajador. No olvidemos que perfectamente pueden desencadenarse enfermedades profesionales en la ejecución de un trabajo ejecutado en el domicilio, por ejemplo lesiones en los órganos de movimiento (tendinitis), lesiones en los órganos de los sentidos (audición) o neurosis profesional. Padecimientos que en nada se diferencian de los que podría sufrir un trabajador de planta, por cuanto no resulta posible relevar al empleador de una labor activa en su prevención.

No puede ni debiera entenderse que un futuro contrato de trabajo a distancia, operará con absoluto desconocimiento de la obligación establecida en el artículo 184 del CT, mediante el cual el empleador está obligado a tomar todas las medidas necesarias para proteger eficazmente la vida y salud de los trabajadores. Por el contrario de conformidad a las particulares características del trabajo a domicilio, se debe adecuar dicha obligación a labores necesarias y plausibles con objeto de asegurar el mandato legal del respeto a la seguridad de los trabajadores.

Sin perjuicio de reconocer el rol activo que le competirá al trabajador a domicilio en ejercicio de la presente modalidad ${ }^{70}$, en mérito de la mentada igualdad de derechos entre los trabajadores de planta con los trabajadores a distancia, urge por parte de la futura norma exigibilidad al empleador en dicha materia. Útil sería por ejemplo, la implementación de visitas del empleador de carácter obligatorio, con objeto de efectuar una revisión previa y regular de las condiciones de higiene y seguridad en que se está ejecutando la labor del trabajador a distancia.

\subsection{LibERTAD SINDiCAL}

En los países de la Unión Europea, resultan ser frecuentes los acuerdos de negociación colectiva que pactan planes piloto de implantación de modalidades de teletrabajo o derechamente norman sentido y alcance de vínculos laborales a distancia. Pese a que por las condiciones del teletrabajador pudiese ser más difícil que las organizaciones sindicales logren captar su atención y participación, debe tenerse en cuenta que muchos de los planes de teletrabajo contemplan su ejercicio, como una modalidad de ejecución a optar por trabajadores de planta cuando han cumplido cierta antigüedad y en cargos que reúnen ciertos requisitos. Por cuanto, si bien es difícil imaginar una reivindicación dada su dispersión natural, no lo es, que esta misma colectividad surja de pares quiénes trabajan parcialmente en dichas labores y se encuentran al momento de ejecutar sus labores en dependencias de la empresa.

Bajo dicha consideración, y fruto de la aplicación del Convenio $\mathrm{N}^{\circ} 177$ de la OIT, la vigencia de la norma sindical en el trabajo a distancia debe ser absoluta, no existiendo verdaderos fundamentos para efectuar restricción en específico, que cercene la equidad entre los derechos de quienes trabajan a domicilio y los que lo hacen desde la misma empresa.

\subsection{Protección de La maternidad}

El trabajo a domicilio debiera mantener un mayor crecimiento en el campo laboral femenino, en tanto, sus características permiten una armónica compatibilización del trabajo con la maternidad ${ }^{71}$, en comparación con el trabajo clásico que se realiza en dependencias de la empresa.

70 Thibault (2000) p. 170.

7 CaAmaño (2010). 
Sin embargo, si bien en el trabajo a domicilio genérico, la presencia de la mujer era mayoritaria. Hoy, la citada Encuesta Casen reveló, por lo menos en materia de teletrabajo que sólo el 23,60\% es ejecutado por mujeres ${ }^{72}$. Punto que debería llevar a reafirmar la necesidad de una legislación que decididamente fomente el trabajo a distancia en un grupo ávido de iniciativas de este tipo.

\section{NECESIDAD DE TUTELA LEGAL}

En razón de las consideraciones expuestas respecto de cada una de las instituciones laborales que impacta el trabajo a distancia, es pertinente observar que nuestra ley debe ser continuamente revisada respecto a los cambios que se producen en las relaciones laborales con objeto de que exista correspondencia entre lo ordenado normativamente y la conducta efectiva de los destinatarios ${ }^{73}$. Hasta la fecha, pese a lo mucho que se ha escrito, no existe legislación específica que regule al trabajo a distancia, figura doctrinal de reciente data, que como se señaló, engloba al trabajo a domicilio y teletrabajo.

De la lectura de la evolución histórica de la normas que han regulado al trabajo a distancia en Chile, podemos observar que en vez de avanzar con los tiempos, sin mayor argumentación jurídica, la desregulación se ha asentado, configurando una indefensión latente y una posición jurídica disminuida de quiénes realizan labores a domicilio. Arraigándose dicha concepción en la práctica jurídica, al punto que de forma inmediata e incorrecta se tiende a suponer la ausencia de contrato de trabajo respecto de actividades ejecutadas desde el hogar para terceros. Luego, aún si en el caso existiera contrato de trabajo, en muchos aspectos no existe la regulación necesaria que impida eventuales escenarios de precarización del vínculo.

Enseguida, apartándonos de las figuras que apuntan a la realización del trabajo independiente, debemos recordar que en el trabajo a distancia, la subordinación puede ser equivalente o mayor incluso en intensidad a la propia de una relación laboral clásica. Por cuanto, no debe olvidarse que pese a lo limítrofe de la figura en comento con el trabajo independiente, requiere una norma laboral que tutele de forma efectiva a dichas relaciones laborales.

La situación actual de anomia jurídica en el tema, es fruto de la arraigada costumbre que la contratación de mano de obra a domicilio, haya sido asimilada por años a la figura del arrendamiento civil de servicios. Lo que lleva en la práctica a un no deseado fomento a vínculos no verdaderamente civiles de trabajo a domicilio. Tal cual advierte Javier Thibault, el teletrabajo puede ser utilizado también como una formula encubierta de reducción de personal, de trabajo precario y mal pagado que propicie la explotación de minorías menos favorecidas, de rebaja en los niveles de protección o de dumping social mediante el desplazamiento de trabajo a países con costes más bajos $^{74}$.Por consiguiente, dejar entregada en manos de la autonomía individual su tratamiento y muchísimos aspectos de su ejecución, produce el particular efecto de reflejar equiparidad respecto de los trabajadores más cualificados, sin embargo, respecto de los menos cualificados podría suponer la pura y simple imposición empresarial ${ }^{75}$.

En el año 2001, investigaciones de la Dirección del Trabajo, alertaban respecto de esta situación, indicando que el Derecho del Trabajo no ha reflejado en su legislación normas que den cuenta suficientemente de la nueva realidad representada por el trabajo a domicilio, lo que se con-

\footnotetext{
Morales y Romanik (2011) p. 26.

López (2004) p. 197.

Thibault (2000) p. 41.

Thibault (2000) p. 42.
} 
trapone con el hecho objetivo de que las personas que se están viendo involucradas en relaciones a las que con o sin fundamento, se les asigna carácter civil en vez de carácter laboral, tiendan a ser cuantitativamente cada vez más numerosas ${ }^{76}$.

La proposición de regulación legal, tiene como contrapartida la promoción del teletrabajo, modalidad asentada de forma exitosa en numerosos países. Como se ha podido comprobar permite innumerables ventajas sociales, tales como la adaptación de la estructura empresarial al desarrollo de las tecnologías de la informática, la promoción del trabajo de discapacitados, su concordancia con un plan expansivo de beneficios a la maternidad, así como una sensible mejora de los problemas de tráfico y locomoción que ha presentado nuestra capital ${ }^{77}$, hechos que sirven para reafirmar la necesidad de un proyecto de ley ad-hoc.

Una futura legislación al respecto deberá presentar una estructura coherente con el funcionamiento de nuestra norma, cuya implementación significará sin duda un fomento del trabajo a distancia. Empero, aquella propuesta de reforma al Código del Trabajo debe contener normas indicadas para proveer de mayor seguridad a las partes que suscriban acuerdos de este tipo, evitando que la omisión en el tratamiento o la autonomía entregada a las partes en algunas materias signifique la permanencia de vicios que el trabajo a domicilio arrastra desde antiguo. En efecto, se observa respecto del Proyecto de Ley $\mathrm{N}^{\circ} \mathrm{N}$ 224-558, que pese a responder al modelo que se propugna en líneas generales, no dedica el estándar idóneo de tutela laboral en materias tales como la distribución de costos operacionales en materiales y/o herramientas, regulación de visitas con objeto de prevenir accidentes del trabajo y/o enfermedades profesionales y responsabilidad en materia de higiene y seguridad, donde traspasa casi íntegramente la responsabilidad al trabajador.

Urge una mayor atención por parte del legislador a dichas materias, más aún cuando se sabe que al menos una parte del universo aplicable del proyecto resultan ser trabajadores de baja calificación e ingresos que exceden con creces el arquetipo clásico proyectado para el teletrabajador, configurando relaciones de trabajo que de ninguna manera merecerían un estándar de tutela menor. Por lo pronto, no debiese suponer el legislador en ellos, una capacidad de negociación tan alta, capaz de distribuir a la par los costos con el empleador, por la vía de un pacto libre. La precaución en dichas materias debe ser aún más aguda, en conocimiento de los abusos cometidos en el trabajo a domicilio desde antes de mediados de siglo, cuya existencia sólo fue considerada como una cifra marginal asociada a deplorables condiciones laborales. Por consiguiente, en la futura legislación no se debiera omitir ciertos mínimos irrenunciables que brinden el sustento necesario para impedir conflictos y situaciones de profunda injusticia.

\section{COMENTARIO FINAL}

Aun manteniéndose la eterna promesa de que teletrabajar sea algún día una alternativa consolidada de ejecución de las actividades laborales, por mientras, quiénes trabajen desde el hogar, siempre responderán a un colectivo reducido.Conclusión que no justifica la inmovilidad seguida por nuestra legislación, que mantiene hasta hoy su negativa a tutelar de forma expresa a un colectivo de trabajadores de existencia cierta.

El desconocimiento de la cantidad exacta de vínculos de subordinación reales a domicilio, no debiese ser obstáculo para entender el desmejorado escenario legal que encuentran vínculos del presente tipo, cuya falta de referencia legal, compromete la seguridad jurídica, generándose n muchos aspectos, una no deseada entrega de su regulación práctica a la autonomía de la voluntad de las partes. 
El altamente probable crecimiento de dicha modalidad, sus comprobadas ventajas como modalidad alternativa de trabajo, así como su concordancia con las añoradas políticas de flexibilidad en el trabajo, aconsejan una mayor atención legislativa a la temática del trabajo a distancia.

Atingente es revisar el camino que han seguido otras legislaciones, las cuáles con éxito han regulado hipótesis similares, protegiendo efectivamente a trabajadores cuyos vínculos probablemente se encontrarían en una situación más precaria de no existir. Tras dichas regulaciones, fueron más los empleadores e incluso administraciones públicas las que se atrevieron a implementar programas pilotos de teletrabajo, siendo actualmente materia de recurrente discusión en contratos colectivos $^{78}$.

En este sentido, se insistirá en que el trabajo a distancia necesita imperiosamente de un pronunciamiento claro de nuestro Código del Trabajo que brinde seguridad a los contratantes nacionales, no sólo regulando sino fomentando la proliferación de esta modalidad de trabajo, en conocimiento de sus múltiples beneficios en la cantidad y calidad del empleo. En dicha regulación debiesen estar incluidas disposiciones relativas a higiene y seguridad, visitas, modalidad de ejecución parcial, determinación de asunción de costos y lugar de ejecución. Todo ello, con el propósito que en todos los ámbitos de la ejecución de la actividad laborativa, efectivamente los tutele una norma de orden público, que evite la generación de vínculos precarios por el sólo hecho de su distancia física con las dependencias de la organización productiva.

Trabajo recibido el 25 de junio y aprobado el 11 de agosto de 2015

\section{BIBLIOGRAFÍA}

Borros, Adriana V. (2008): Teletrabajo su protección en el Derecho Laboral. (Buenos Aires. Argentina, Cathedra Jurídica).

CaAmaño Rojo, Eduardo (2005): "Las transformaciones del Trabajo, la crisis de la relación de trabajo normal y el desarrollo del empleo atípico", Revista de Derecho vol. XVIII, No 1.

CAAmaño Rojo, Eduardo (2010): "El teletrabajo como una alternativa para promover y facilitar la conciliación de responsabilidades laborales y familiares", Revista de Derecho de la Pontificia Universidad Católica de Valparaiso, No35.

Cámara de Comercio de Barcelona: Página Web. Disponible en:http://intranet.oit.org.pe/WDMS/bib/virtual/ coleccion_tem/teletrab/ecommerce_11 esp.pdf

Cámara de Diputados (2010): Mensaje No224-558 del 20 de agosto del 2010.

Carro Igelmo, Alberto José (1992): Historia Social del Trabajo. (Barcelona, Bosch Casa Editorial S.A.)

Centro de Investigación y Documentación del Ministerio de Trabajo y Asuntos Sociales (2000): Perspectiva Internacional del Teletrabajo. Nuevas formas de trabajo en la Sociedad de la Información. (Madrid)

Confederación Europea de Sindicatos y Organizaciones Patronales Europea (2002): Acuerdo Marco Europeo sobre el Teletrabajo.

Contreras Abarca, Javiera (2001): Innovaciones Tecnológicas; Derecho del Trabajo-Chile. Tesis Licenciado en Ciencias Jurídicas y Sociales (Santiago, Pontificia Universidad Católica de Chile).

El Mercurio Ontine (2010): "Cámara de Diputados aprueba el proyecto que regula el trabajo a distancia”. Disponible en: http://www.emol.com/noticias/economia/2010/11/10/446588/camara-de-diputados-aprueba-proyectoque-regula-el-trabajo-a-distancia.html

Feres, María Ester (2011): Mujeres asalariadas viven en el peor de los mundos. Selección de Artículos de Le Monde Diplomatique. 
Isaías Rodríguez Reyes / Análisis jurídico a la figura del trabajo a distancia

Gamonal Contreras, Sergio (2010): Trabajo y Derecho. (Santiago, Legal Publishing).

Guajardo Donoso, Rodrigo (2008): Subordinación o dependencia y teletrabajo. Tesis Licenciado en Ciencias Jurídicas y Sociales. (Santiago, Pontificia Universidad Católica de Chile).

Guidi Leje, Andrés (2000): La Problemática Legal del Teletrabajo en Chile. (Santiago, Pontificia Universidad Católica de Chile. Facultad de Derecho).

Henríquez Riquelme, Helia (2005): “El Trabajo a Domicilio: Una transformación que requiere afinar el diagnostico”, en: Departamento de Estudios Dirección del Trabajo, Trabajo a Domicilio en el Siglo XXI, Tres miradas sobre el Teletrabajo.

JURI SABAG, Víctor (2006): El teletrabajo: la nueva forma de trabajo.(Santiago, Lexis Nexis).

Kravetz, Dennis J. (1994): La revolución de los recursos bumanos. (Madrid).

López, Diego (2004): Derechos, Trabajo y Empleo.(Santiago, LOM Ediciones).

Lizama Portal, Luis (2004): "Derecho a la intimidad de los trabajadores y Nuevas Tecnologías de la Información y Comunicación (NTIC)”, Anuario de Derecho del Trabajo y Seguridad Social N³.

Montero, Cecilia (2010): La formación de capital humano en empleos atípicos: el caso del trabajo a domicilio. (Santiago, CEPAL).

Morales Varas, Gabriela y Romanik Foncea, Katy (2011): Una mirada a la figura del teletrabajo. Informe de Actualidad Laboral $N^{\circ} 1$.(Santiago, Dirección del 'Trabajo).

Organización Internacional del Trabajo (1994): Conferencia Internacional del Trabajo, 82 a, Reunión: Trabajo a Domicilio, Quinto Punto del Orden de día, Informe V. (Ginebra)

Ortiz Chaparro, Francisco (1996): El teletrabajo: una nueva sociedad laboral en la era de la tecnologia. (Madrid, McGraw-Hill).

Palavecino, Claudio (1999): "La Subordinación laboral, una relación en permanente cambio", Revista Laboral Chilena $\mathrm{N}^{\circ} 9$.

Repsol (2012): “Libro Blanco del Teletrabajo Repsol”. Disponible en: http:/www.repsol.com/imagenes/es_es/libro_ blanco_tcm7-627218.pdf

SALAZAR, Cristián: "El teletrabajo una ventana que promueve la inclusión”. Disponible en: www.teletrabajo.cl.

SÁnchez Gálviz, Martha (2012): Un acercamiento a la minedición del teletrabajo: Evidencia de algunos países de América Latina. (Santiago, CEPAL).

SANGuinetTI, W. (1996): “La dependencia y las nuevas rẹalidades económicas y sociales: ¿uun criterio en crisis?”,Temas Laborales $\mathrm{N}^{\circ} 40$.

Selamé, Teresita (2005): "Trabajo a Domicilio en el Siglo XXI", en: Departamento de Estudios Dirección del Trabajo, Trabajo a Domicilio en el Siglo XXI, Tres miradas sobre el Teletrabajo.

Sempere, Antonio y Kahale, Djamil (2013): Teletrabajo (Ediciones Francis Lefebvre).

ThaYer, Williamy Novon, Patricio (2006): Manual de Derecho del Trabajo, Derecho Individual, Tomo IV Contrato de Trabajo. (Santiago, Editorial Jurídica de Chile).

Tinbault Arnndı, Javier (2000): Teletrabajo: Análisis Jurídico Laboral. (España, Editorial Consejo Económica y Social)

UGarte Cataldo, José Luis (2007): El nuevo derecho del trabajo. (Santiago, Lexis Nexis)

\section{NORMAS CITADAS}

Código del Trabajo, de 6 de febrero de 1931.

Organización Internacional del Trabajo (1996): Convenio Internacional $N^{\circ}$ 177, sobre el trabajo a domicilio. 